\title{
O professor universitário novato: tensões, dilemas e aprendizados no início da carreira docente
}

\author{
The novice university professor: tensions, \\ dilemmas and learning in early teaching careers
}

\author{
Leila Inês Follmann Freire ${ }^{1}$ • Carmen Fernandez ${ }^{2}$
}

\begin{abstract}
Resumo: O presente trabalho tem por objetivo analisar como docentes do Ensino Superior de uma universidade pública percebem os diferentes agentes do campo educacional, e como as tensões e dificuldades são gerenciadas no início da profissão, partindo da noção de campo de Bourdieu. Nossos dados se basearam em entrevistas semiestruturadas, que foram analisadas por Análise de Conteúdo. Nossos resultados revelam dificuldades relacionadas à gestão de sala de aula e semelhanças entre professores com e sem experiência prévia no que diz respeito: à insegurança didática, ao valor dado ao apoio (ou não) dos colegas de trabalho, e ao número de atividades desempenhadas. Revela-se, ainda, uma relação de dominação dos professores mais experientes sobre os novatos no trabalho universitário. Essas relações de poder refletem, claramente, a diferenciação de capital cultural e simbólico de quem adentra um novo campo, revelando as estruturas mais gerais de um campo na perspectiva de Bourdieu.
\end{abstract}

Palavras-chave: Ensino Superior. Professor universitário. Análise de conteúdo. Capital cultural. Desenvolvimento profissional.

\begin{abstract}
This study aims to examine how professors in higher education at a public university perceive the different agents of the educational field and how the tensions and difficulties are managed at the beginning of the profession based on the notion of field from Bourdieu. Our data were based on semi-structured interviews and were analyzed by content analysis. Our results reveal difficulties related to the management of the classroom and similarities between teachers with and without previous experience with regard to insecure didactic value given to support (or not) of coworkers and the number of activities performed. It is furthermore a relationship of domination of experienced teachers on novices in university work. These power relations clearly reflect the differentiation of cultural and symbolic capital and who enters a new field, revealing the more general structures of a field from the perspective of Bourdieu.
\end{abstract}

Key words: Higher education. University professors. Content analysis. Cultural capital. Professional development.

\footnotetext{
${ }^{1}$ Departamento de Métodos e Técnicas de Ensino, Universidade Estadual de Ponta Grossa, Rua Carlos Cavalcanti, 4748, CEP 84030-900, Ponta Grossa, PR, Brasil. E-mail: <leilafreire@usp.br>

${ }^{2}$ Departamento de Química Fundamental, Instituto de Química (IQ), Universidade de São Paulo (USP), São Paulo, SP, Brasil.
} 


\section{Introdução}

As pesquisas sobre o professor do Ensino Superior ${ }^{3}$, o início de sua trajetória profissional e o seu desenvolvimento pessoal ainda avançam timidamente se comparadas àquelas envolvendo outros níveis de ensino. Mesmo assim, pesquisas neste nível vêm aumentando a cada década e reforçam a necessidade de se explorar a situação do docente universitário e detalhes do seu trabalho cotidiano, a fim de contribuir para a melhoria da formação ofertada neste nível de ensino. Diante disso, alguns questionamentos norteiam esta investigação: Como é o início da experiência de professores universitários na docência no Ensino Superior? Há diferenças nessas vivências iniciais entre aqueles que tiveram experiências docentes anteriores à docência universitária? Quais as relações entre os diferentes agentes (instituição, alunos e professor) presentes nesse processo?

A função de professor do Ensino Superior no Brasil abarca uma série de profissionais, entre eles, aqueles que formam futuros professores, aqueles que formam profissionais liberais, que formam os bacharéis e tecnólogos. Todos os docentes que atuam nas instituições de Ensino Superior devem ter uma formação mínima, exigida por lei. No Brasil, essa formação necessária para atuar como docente no magistério superior está definida no artigo 66 da Lei de Diretrizes e Base da Educação Nacional, e aponta que “[...] far-se-á em nível de pós-graduação, prioritariamente em programas de mestrado e doutorado” (BRASIL, 1996, p. 25).

Um cenário preocupante sobre a situação da formação dos professores do Ensino Superior brasileiro é retratada por Mizukami (2002, p. 151), ao inferir que a formação para a docência “[...] no Ensino Superior é ainda território que apresenta iniciativas tímidas [...] Boa parte das iniciativas, no entanto, tem permanecido no âmbito das políticas institucionais de cada universidade".

A Coordenação de Aperfeiçoamento de Pessoal de Nível Superior - CAPES (2002) oficializou o Estágio Docência, a partir da Portaria No 52, de 26 de setembro de 2002, como uma forma de docência orientada aos pós-graduandos, mas apenas aos bolsistas daquela agência financiadora. Essa iniciativa, mesmo que isolada, aponta para uma preocupação que vem aumentando no meio acadêmico.

Pimenta e Anastasiou (2002) apontam que, muitas vezes, os professores do Ensino Superior das diferentes áreas preferem ser identificados como profissionais autônomos: físico, advogado, médico ou professor universitário, pois o título de professor de Física, Direito, Medicina ou de qualquer outra área do conhecimento, sozinho, parece sugerir uma identidade menor, como revela o trecho a seguir:

\footnotetext{
${ }^{3}$ Optamos por usar o termo em inglês university professor no título do trabalho, no resumo e nas palavras, ao invés do uso de university teacher, para diferenciar o professor universitário do professor de outros níveis de ensino (professor, para professor universitário e colleges e teacher, para professor do Ensino Médio). Assumimos o uso desse termo alertando o leitor que essa diferenciação é válida nos Estados Unidos e em alguns países europeus. Mas, por exemplo, na Alemanha e na Inglaterra, só recebe esse título (professor) o professor titular na carreira universitária, o que torna o uso desse termo uma referência para poucos. Nos Estados Unidos, o professor titular é denominado de full professor. Neste trabalho, university professor diz respeito a qualquer professor do Ensino Superior, independente de serem titulares ou não. No nosso caso, estamos nos referindo a professores universitários que atuam em cursos de licenciatura.
} 
Essa questão aponta para a problemática profissional do professor de ensino superior, tanto no que se refere à identidade, que diz sobre o que é ser professor, quanto no que se refere à profissão, que diz sobre as condições do exercício profissional. (PIMENTA; ANASTASIOU, 2002, p. 36)

$\mathrm{Na}$ docência universitária, podem-se encontrar quatro grupos de professores: (i) profissionais de várias áreas do conhecimento que se dedicam à docência em tempo integral; (ii) profissionais liberais que se dedicam ao magistério algumas horas por semana; (iii) docentes da área pedagógica e das licenciaturas, que atuam tanto no Ensino Básico quanto no Superior; e (iv) profissionais da área de educação e das licenciaturas que atuam em tempo integral na universidade (BEHRENS, 2001). Segundo a autora, são os que atuam no primeiro grupo que se envolvem mais efetivamente com alunos (por um período maior da formação inicial destes, se comparados aos outros grupos listados pela pesquisadora), com os seus pares, com o departamento e a instituição, e são os responsáveis pela maior parcela das publicações científicas utilizadas no meio acadêmico. Por outro lado, muitos professores deste grupo ensinam o que nunca experienciaram. Para Oliveira (2008, p. 22), muitas vezes, essa “[...] situação agrava-se quando o professor não tem nenhuma formação pedagógica e reproduz a proposta dos professores que atuaram em sua própria formação, tão-somente repassando conhecimentos".

Há mais de 55 anos, concluiu-se, em uma conferência da American Council on Education, que “[...] o professor universitário é o único profissional de nível superior que entra para uma carreira sem que passe por qualquer julgamento de pré-requisitos em termos de competências e de experiência prévia no domínio das habilidades de sua profissão (BALZAN, 1997, p. 1).

Não se trata de desconsiderar a necessidade e o valor da titulação para a formação profissional dos docentes do Ensino Superior, mas de levar em conta que há outros aspectos tão ou mais fundamentais que a qualificação stricto sensu. Oliveira (2008, p. 33) aponta que “[...] um título, por si só, não garante que o mestre ou doutor será um exímio professor e pesquisador ou que possua as competências necessárias para atuar no ensino superior".

Ao defender uma dissertação ou tese, comprova-se a habilidade de conduzir uma pesquisa e dissertar sobre ela, e não, necessariamente, as habilidades e conhecimentos para ser um docente.

No entanto, há os que superam suas dificuldades e aprimoram seus conhecimentos e competências, tornando-se autodidatas em função do interesse e do entusiasmo que os envolve no exercício da profissão. São estes os formadores que se identificam com sua profissão.

Pimenta e Anastasiou (2002, p. 77) defendem a ideia de que

[...] o processo identitário constrói-se pelo significado que cada professor confere à atividade docente no seu cotidiano, com base em seus valores, em seu modo de situar-se no mundo, em sua história de vida, em suas representações, em seus saberes, em suas angústias e anseios, no sentido que tem em sua vida o ser professor. 
Entretanto, Nóvoa (1995) alerta que esse é um processo que necessita de tempo para refazer identidades, acomodar inovações e assimilar mudanças. E Zabalza (2004, p. 141) acrescenta que “[...] o exercício da profissão e seu domínio não ocorrem por uma transferência direta de sabedoria divina. Não se pode supor que um jovem que ingressa como professor na universidade esteja preparado (mesmo que seja doutor e competente em pesquisa) para enfrentar a docência".

O objetivo deste trabalho não é discutir os aspectos da construção da identidade docente, pois, para isso, seria necessário um escopo teórico maior e um olhar direcionado para os diferentes aspectos da identificação profissional, especificamente da profissionalização docente. No entanto, pretende-se entender como os diferentes agentes do campo educacional, em particular do Ensino Superior, são percebidos pelos docentes, e como as tensões e dificuldades são gerenciadas no início da profissão. Para tanto, é preciso compreender que a transferência direta, a que se refere Zabalza (2004), não ocorre, e que o domínio da profissão é construído em contato com o ambiente e os diferentes agentes envolvidos no trabalho profissional.

Então, considerar as tensões decorrentes da cultura organizacional da instituição (ZABALZA, 2004) - sobretudo o estilo de direção e gestão, a legislação e o contato com instâncias reguladoras do trabalho docente, além dos agentes presentes nas situações de ensino dos professores universitários (os alunos) e os dilemas relativos ao ensino de conteúdos específicos - parece-nos fundamental para compreender como os professores gerenciaram e superaram suas dificuldades no início da carreira universitária.

Para compreendermos as tensões e dificuldades dos docentes, entendidos como constituintes de um espaço social específico, que tem suas características próprias (que, inclusive, os diferencia do espaço social da escola básica, especialmente no que tange ao reconhecimento social e as exigências burocráticas e de trabalho - aliar ensino, pesquisa e extensão, por exemplo), nos aproximamos do referencial teórico de Bourdieu, no que diz respeito à noção de Campo. Essa noção será brevemente explicitada na sequência do texto.

\section{A noção de campo em Pierre Boudieu}

Nas obras do sociólogo Pierre Bourdieu, uma das noções centrais é a de Campo. As discussões sobre o Campo entrelaçam-se com outras noções, como as de Capital e Habitus, e perpassam suas obras em diversos momentos, abordando as mais diversas áreas: moda, literatura, ciência, religião, casamento, educação, política, entre outras. O campo é um espaço social que possui uma estrutura particular, com objetivos específicos, que funciona de forma relativamente autônoma em relação a outros espaços sociais. Ao definir um Campo, Bourdieu se refere a um “[...] universo no qual estão inseridos os agentes e as instituições que produzem, reproduzem ou difundem a arte, a literatura ou a ciência. Esse universo é um mundo social como os outros, mas que obedece a leis sociais mais ou menos específicas” (BOURDIEU, 2004, p. 20).

Ainda em relação ao campo, o autor diz que são "[...] espaços estruturados de posições (ou de postos) cujas propriedades dependem da sua posição nesses espaços e que podem ser analisadas independentemente das características dos seus ocupantes (em parte determinadas por elas)" (BOURDIEU, 1983, p. 119). 
Cada campo é um recorte da sociedade, formado pela afinidade ou pela diferenciação de interesses dos seus agentes, que partilham o mesmo sentido de jogo, de modo a viabilizar uma luta pelo poder simbólico em disputa no campo. Esse mesmo sentido de jogo, definido como as "paradas em jogo", os objetos de disputa, aquilo que é considerado valioso no campo, é o que o sustenta. Esses interesses comuns são percebidos por quem faz parte daquele campo, e não o são "[...] por alguém que não tenha sido construído para entrar nesse campo (cada categoria de interesses implica indiferença perante outros interesses, outros investimentos, assim votados a serem percebidos como absurdos, insensatos, ou sublimes, desinteressados)" (BOURDIEU, 1983, p. 120).

É comum a analogia do campo com um jogo, com suas regras, criadas pelos seus jogadores, mas que nem sempre são claras para todos que participam do jogo. Alguns agentes ou instituições são capazes de criar ou alterar as regras, e o fazem por conta do capital que possuem e da posição que ocupam no campo. Assim, ocorre uma luta constante entre os agentes do campo que detêm maior quantidade de capital e ditam as regras do jogo, as normas do campo e definem qual é, num dado momento, o conjunto de objetos importantes para o campo. Do outro lado, há os que ameaçam a posição dos dominantes, conquistando capital suficiente para se fazerem importantes.

A luta entre os agentes que possuem diferentes capitais é comum, e determina o estado do campo em cada momento. Descrever um campo como um mundo físico, comportando as relações de força e as relações de dominação, implica tensões presentes naturalmente nele. E são essas lutas e jogos de interesse que geram tensões próprias de cada campo, e acontecem em torno da posição de cada um no campo e dos interesses comuns e específicos que cada agente tem. Considerando a visão de Bourdieu de que

[...] os agentes (indivíduos ou instituições) caracterizados pelo volume de seu capital determinam a estrutura do campo em proporção ao seu peso, que depende do peso de todos os outros agentes, isto é, de todo o espaço. Mas, contrariamente, cada agente age sob a pressão da estrutura do espaço que se impõe a ele tanto mais brutalmente quanto seu peso relativo seja mais frágil. (BOURDIEU, 2004, p. 24)

podemos inferir que as disputas e os interesses em cada campo dependem, também, da posição que cada agente ocupa e do seu poder no campo. Essa diferença de capital e de posição gera tensões entre os agentes e no próprio campo, que vão dando novas configurações a esse espaço social e criando novas regras de convivência. Para o autor ainda,

[...] a estrutura do campo é um estado da relação de força entre os agentes ou as instituições envolvidas na luta ou, se se preferir, da distribuição do capital específico que, acumulado no decorrer das lutas anteriores, orienta as estratégias posteriores. Esta estrutura, que está no princípio das estratégias destinadas a transformá-la, está ela própria sempre em jogo: as lutas cujo lugar é o campo têm por parada em jogo o monopólio da violência legítima (autoridade específica) que é característica do campo considerado, quer dizer, em última análise, a conservação ou 
a subversão da estrutura da distribuição do capital específico. (BOURDIEU, 1983, p. 120-121)

Montagner e Montagner (2011) fazem uma analogia do campo com um fractal, pois, assim como na estrutura de um fractal, a estrutura construída historicamente num campo permanece e se reproduz, assumindo formas levemente diferenciadas de acordo com as oposições e confrontos que ocorrem.

\section{Problemática de investigação}

Levando em conta as características de um campo propostas por Pierre Bourdieu, consideramos o conjunto de professores do Ensino Superior e suas relações profissionais com estudantes e a própria instituição em que trabalham como membros de um subcampo dentro do campo profissional que está inserido no campo universitário. O funcionamento do subcampo da docência universitária tem: suas próprias regras de funcionamento, diferentes posições determinadas em função do capital que possuem os agentes, um habitus de classe coletivo, ações que permeiam a prática profissional que se reproduzem historicamente, e tensões que reorientam as ações dentro desse espaço social.

Na perspectiva bourdieusiana um campo é tão mais autônomo quanto mais se consome os produtos desse campo, indicando a necessidade de um polo produtor e outro consumidor dentro do próprio campo. A partir dessa ideia e dos dados empíricos que analisamos, compreendemos que existe um espaço na academia para a produção da docência (embora ele não seja tão valorizado como os demais) e que ela é fortemente consumida pelos graduandos, já que só se faz docência na universidade em função de um objetivo maior: formar na teoria e na prática os futuros profissionais.

Compreendendo a docência universitária como um subcampo que comporta características do campo em que está inserido, alguns questionamentos norteiam esta investigação: Como é o início da experiência de professores universitários na docência no ensino superior? Há diferenças nessas vivências iniciais entre aqueles que tiveram experiências docentes anteriores à docência universitária? Quais as relações entre os diferentes agentes (instituição, alunos e professor) presentes nesse processo? Diante disso, temos por objetivo apontar como os diferentes agentes do campo educacional, em particular do ensino superior, são percebidos pelos docentes e como as tensões e dificuldades são gerenciadas no início da profissão. Doravante chamaremos este espaço social de campo da docência universitária, embora reconheçamo-lo como um subcampo de um campo maior, atravessado no campo profissional que constitui parte do campo universitário. Apenas para fins de fluidez na leitura adotaremos a uso da palavra campo, ao invés de subcampo, quando nos referirmos à docência universitária.

\section{Desenho metodológico da pesquisa}

Este trabalho insere-se numa pesquisa maior sobre a influência da ação formativa de professores do Ensino Superior na prática de ensino de seus licenciandos. Aqui foram utilizados 
dados de entrevistas semiestruturadas, realizadas com dez professores de uma universidade pública do estado do Paraná, Brasil. As entrevistas foram conduzidas com características do método biográfico, e foram gravadas em áudio, transcritas, e o seu conteúdo revisado pelos entrevistados que autorizaram a utilização dos dados para a pesquisa acadêmica.

A pesquisa tem caráter qualitativo; os dados foram organizados para cada professor a partir de um perfil mínimo estabelecido para cada entrevistado, e foram analisados com base na metodologia de Análise do Conteúdo (BARDIN, 2003). As categorias de análise foram definidas a partir da análise dos dados e emergiram em função das falas dos participantes, portanto, refletem as ideias e pensamentos dos professores, e não se aliam a algum referencial teórico específico.

Para garantir que seja preservada a identidade dos entrevistados, os professores serão chamados de P1, P2, P3, até o professor P10.

\section{Perfil dos participantes}

Todos os participantes da pesquisa trabalharam com a mesma turma de um curso de Licenciatura em Química (concluintes do curso em 2011) de uma universidade pública no estado do Paraná, Brasil, sendo, portanto, expoentes do atual período histórico, contemporâneos da atual geração de jovens universitários. Essa escolha possibilitou duas condições necessárias à pesquisa: vinculação a uma mesma instituição de Ensino Superior e convivência com os mesmos alunos de graduação. A escolha por professores universitários que atuassem numa mesma instituição e com o mesmo grupo de licenciandos favoreceu a pouca variação dos aspectos intrínsecos ao grupo de acadêmicos, como a origem regional, diferenças culturais, e proporcionou um nível intelectual aproximado entre os licenciandos, uma vez que todos ingressaram no mesmo processo seletivo. Além disso, a vinculação a uma mesma instituição de ensino equaliza os processos burocráticos e as cobranças institucionais sobre o professor.

Os entrevistados trabalharam com as disciplinas da área pedagógica geral, da prática de ensino de química e da área específica de conhecimento (química e afins) com a mesma turma de acadêmicos (concluintes do curso em 2011) de um curso de Licenciatura em Química de uma universidade pública no estado do Paraná, Brasil. Os professores P1, P2, P3, P4, P5 e P6 ministraram disciplinas da área específica de química e afins, como a física, por exemplo. P7 ministrou disciplinas pedagógicas gerais, como a Didática, e P8, P9 e P10 trabalharam com disciplinas da prática de ensino de química. No Quadro 1, estão especificadas: as áreas de formação dos professores, a experiência na docência universitária (em termos de tempo) e em outros níveis educacionais.

Dos dez professores investigados, somente três não haviam tido experiência como docentes regulares em escolas da Educação Básica antes de ingressarem na docência no Ensino Superior (embora um destes professores, P8, já tivesse dado aula particular), e sete haviam tido experiências em outros níveis de ensino, especificados no Quadro 1. 
Freire, L. I. F.; Fernandez, C.

Quadro 1. Características de formação e experiência profissional dos professores

\begin{tabular}{|c|c|c|c|c|}
\hline \multirow[b]{2}{*}{ Entrevistado } & \multicolumn{2}{|c|}{ Área de formação } & \multicolumn{2}{|c|}{ Experiência profissional } \\
\hline & Graduação & $\begin{array}{l}\text { Pós-graduação } \\
\text { (área) }\end{array}$ & $\begin{array}{c}\text { Tempo de } \\
\text { docência } \\
\text { no Ensino } \\
\text { Superior }\end{array}$ & $\begin{array}{c}\text { Experiência } \\
\text { como professor } \\
\text { anterior à docência } \\
\text { universitária }\end{array}$ \\
\hline P1 & Licenciatura em Química & Química & 25 anos & $\begin{array}{l}\text { Ensino Fundamental } \\
\text { e Médio }\end{array}$ \\
\hline P2 & Bacharelado em Química & Química & 10 anos & Nenhuma \\
\hline P3 & Bacharelado em Química & Química & 10 anos & Nenhuma \\
\hline P4 & $\begin{array}{l}\text { Licenciatura e Bacharelado } \\
\text { em Química }\end{array}$ & Química & 10 anos & Ensino Médio \\
\hline P5 & Farmácia e Bioquímica & Bioquímica & 3 anos & Ensino Médio \\
\hline P6 & $\begin{array}{l}\text { Licenciatura e Bacharelado } \\
\text { em Química }\end{array}$ & Química & 10 anos & Educação Infantil \\
\hline P7 & Pedagogia & Educação & 21 anos & $\begin{array}{l}\text { Educação Infantil e } \\
\text { Ensino Fundamental }\end{array}$ \\
\hline P8 & $\begin{array}{l}\text { Licenciatura e Bacharelado } \\
\text { em Química }\end{array}$ & $\begin{array}{l}\text { Ciência e } \\
\text { Tecnologia de } \\
\text { Alimentos }\end{array}$ & 2 anos & $\begin{array}{l}\text { Somente } \\
\text { aulas particulares }\end{array}$ \\
\hline P9 & Licenciatura em Química & Química & 5 anos & Ensino Médio \\
\hline P10 & Licenciatura em Química & $\begin{array}{l}\text { Ensino de } \\
\text { Ciências }\end{array}$ & 2 anos & $\begin{array}{l}\text { Ensino Fundamental } \\
\text { e Médio }\end{array}$ \\
\hline
\end{tabular}

Fonte: Elaborado pelos autores, com base no instrumento de coleta utilizado.

\section{Resultados e discussão}

Para as análises, fez-se, inicialmente, uma leitura flutuante do texto das entrevistas. Essa leitura permitiu identificar três eixos de análise em torno dos três principais questionamentos que orientaram a pesquisa: (A) relativos ao início da experiência de professores universitários na docência no Ensino Superior; (B) sobre as possíveis diferenças nessas vivências iniciais entre aqueles que tiveram experiências docentes anteriores à docência universitária e aqueles professores que não haviam lecionado ainda; e (C) sobre as relações instituídas entre os diferentes agentes do Campo da Docência Universitária. 
Cada um destes eixos se desdobra em diferentes núcleos de análise e categorias, que serão apresentadas e discutidas na sequência do texto de modo separado, com o intuito de organizar a exposição dos dados e ideias discutidas. Ao final do texto, procuramos traçar aproximações entre os diferentes eixos, e estabelecer um panorama geral de como foi o início da docência universitária para o grupo de professores pesquisados.

\section{Eixo A - Início da experiência de professores universitários}

No primeiro eixo, guiado pela questão 'Como é o início da experiência de professores universitários na docência no Ensino Superior?’, dois núcleos de análise foram evidenciados. Um primeiro, relativo às tensões e dilemas enfrentados no início da docência universitária, em que foram agrupadas as categorias: (a) relacionamento com colegas de trabalho; (b) relacionamento com alunos; (c) relacionamento com instâncias institucionais; (d) gestão de sala de aula; (e) insegurança didática; e (f) domínio dos conhecimentos a ensinar. Os três primeiros aproximam-se de aspectos de uma dimensão pessoal, enquanto os três últimos alinham-se mais à dimensão profissional (ZABALZA, 2004), embora, algumas colocações dos discursos dos professores perpassem mais de uma dimensão do trabalho docente.

Outro núcleo que evidenciamos na leitura prévia foi o das ações para superação das dificuldades encontradas no início da vida de professor universitário. Nas falas dos docentes, apareceram cinco grandes grupos, chamados de categorias: (g) envolvimento com outros agentes/instâncias institucionais; (h) esforço pessoal; (i) experiência; (j) discussões e planejamentos coletivos; e $(\mathrm{k})$ planejamento das ações didáticas.

$\mathrm{Na}$ apresentação e discussão dos resultados, trabalharemos com estes dois núcleos de modo separado, mas, ao final, serão destacadas as relações pertinentes entre as diferentes categorias.

\section{Eixo A: Núcleo 1 - tensões e dilemas}

A maioria dos professores aponta que passou por dilemas e tensões ao começar a trabalhar na universidade, muitas delas expressas em dificuldades de como ensinar num curso de graduação, relacionadas: à gestão de classe, ao pouco domínio dos conhecimentos a ensinar, à insegurança de não conseguirem expressar didaticamente tudo o que sabem sobre um conteúdo específico, entre outras. O relacionamento com os diferentes agentes do Ensino Superior (alunos de graduação, colegas de trabalho - professores ou técnicos - e instâncias comumente constituídas no Ensino Superior - colegiados, departamentos, grupos de pesquisa, comissões institucionais etc.) também esteve presente na fala dos professores, ora apontando dificuldades encontradas, ora relatando apoio recebido.

Categoria A.1.a.) Relacionamento com colegas de trabalho

Na categoria 'Relacionamento com colegas de trabalho' (com 22 trechos de entrevista dos professores P1, P3, P4, P6, P7, P8, P9 e P10), os temas que emergiram a partir das respostas dos professores se referem ao apoio recebido de colegas de trabalho (professores, técnicos de laboratório e chefes de departamento), como: o empréstimo de material para disciplinas espe- 
cíficas; a agilidade na liberação de uso dos espaços físicos na instituição; a disponibilidade de organização de horários por parte da chefia imediata, de modo a distribuir a carga horária do professor novato durante a semana, não o sobrecarregando com muitas aulas num mesmo dia; o convite para participação em grupos de estudos por afinidade de áreas de atuação.

Também, há que se ressaltar, como aspecto positivo apontado pelos docentes entrevistados, a importância atribuída, pelos professores iniciantes, ao trabalho coletivo, considerando-o importante para seu desenvolvimento profissional, além de discursos que apontam para o aprendizado com os professores mais experientes. Isso aponta para uma das características do campo dos formadores, o jogo de posições que existe entre os seus agentes e que o "define a estrutura de um campo num dado momento é a estrutura da distribuição do capital científico entre os diferentes agentes engajados nesse campo" (BOURDIEU, 2004, p. 26). A posição de novato, aprendiz da docência no Ensino Superior, é assumida sem muitos questionamentos em função do cabedal teórico e prático acumulado pelos professores mais experientes. Por exemplo, "eu lembro que a professora Maria ${ }^{4}$ que quando eu passei como efetiva, ela me chamou, pra conversar, dizendo que qualquer ajuda que eu precisasse ela estava à disposição, pra tudo" [P9].

Os professores novos reconhecem aqueles mais experientes, contribuindo para a diferenciação de posições dentro de um campo. O capital acumulado pela experiência docente não é sequer questionado ou discutido, pois o mais experiente é visto como um: "referencial, é um bom referencial pra isso [...] É, eu sempre vou me espelhando um pouco nisso, eu tenho sempre um referencial em mim" [P6].

A vontade de fazer coisas novas, de assumir as tarefas rotineiras, de trabalhar com muito afinco, foi citada pelos professores como uma característica do início da docência e que era, de certo modo, diminuída pelos agentes mais antigos do campo. Aponta, novamente, para uma tensão interna, pois o interesse pelas questões próprias do campo (o trabalho do docente universitário) pode levar a um reconhecimento maior, um capital simbólico maior, o que pode fomentar a mudança nas posições do campo.

Ainda nesta categoria, duas grandes tensões foram apontadas pelos professores. A ausência de objetivos partilhados por todos os agentes, indicando que os interesses pessoais podem fomentar a luta por posições e redefini-las no campo. Embora todos sejam professores de um mesmo curso de licenciatura, os objetivos de formação podem ser concorrentes. Isso é considerado comum num campo, que vai sempre se reconfigurando, mas mantém a estrutura de posições. Em um dado momento, os agentes com menos capital (hereges) podem ascender, resultando numa troca de posições que nem sempre é bem aceita por todos os membros do campo. A dificuldade de convivência pessoal e apoio profissional dos outros professores foi um tema recorrente na fala de P4, P8 e P9. Por exemplo, na fala de P9: "por outro lado quando eu peguei [disciplina $\mathrm{x}$ ], como efetiva, teve professores que não me... nunca tinham material, tanto que acabou o ano e não me deu o material e não me ajudou em nada".

Esta disputa pelo poder (caracterizada pelo não-fornecimento de apoio a um colega iniciante) parece-nos um dilema comum a qualquer campo, mas que, além de caracterizar o

\footnotetext{
${ }^{4}$ Os nomes foram trocados para preservar a identidade dos participantes da pesquisa e dos colegas de trabalho daqueles professores.
} 
campo dos professores do Ensino Ssuperior, pode trazer consequências a outros agentes, como os alunos de graduação. Um professor que não se dispõe a partilhar seu conhecimento com um colega, não está disposto a contribuir para o desenvolvimento do campo, mas busca 'defender' a sua posição ao reconhecer que "[...] é a posição que eles ocupam nessa estrutura que determina ou orienta, pelo menos negativamente, suas tomadas de posição” (BOURDIEU, 2004, p. 23). A dificuldade de relacionamento com colegas docentes mais experientes, a falta de solidariedade e o comportamento de indiferença, pode ser reflexo da exacerbação dos valores neoliberais em que a lógica predominante é o pragmatismo e o incentivo à competição individual se estabelece por meio de sistemas de avaliação externa que priorizam a ação individual, em detrimento da coletiva (CUNHA, 2005).

Categoria A.1.b.) Relacionamento com alunos

Na segunda categoria "Relacionamento com alunos" (total de 21 trechos categorizados, de P1, P6, P7, P8, P9, P10), os professores apontam para uma relação desigual com os alunos em termos de conhecimento específico da área de formação, marcada pela superioridade do docente. Abordam essa situação como sendo a visão dos alunos e, também, dos professores. $\mathrm{O}$ conhecimento específico do conteúdo é o balizador para a detenção de maior capital cultural, e gera um poder simbólico superior. A dependência dos alunos em relação ao conhecimento é grande. Por outro lado, os professores dizem que se sentem avaliados pelos alunos, "eu sei que eu só to sendo avaliada là' (P6), percebem que são exigentes com eles, mas que também são exigidos em termos de dedicação ao trabalho de ensinar.

Dois professores (P9 e P10) apontaram a relação com os alunos como um espaço de troca de experiência e muito diálogo, e ressaltaram a importância que atribuem aos alunos, não os vendo como seres submissos, mas que podem compor juntos a configuração do campo da docência no Ensino Superior.

Uma situação que foi apontada por dois docentes (P7 e P9) parece comum aos professores iniciantes: ser confundido com aluno (FELDKERCHER; ZANCHET, 2012). Por não terem muita diferença de idade e não serem reconhecidos como ocupantes de postos importantes dentro do campo, os professores em início de carreira são confundidos com alunos, e se apoiam na suposta superioridade do cargo que ocupam para manter (e, quiçá, ascender!) posições mais valorizadas. Com o passar do tempo e o ganho de capital simbólico, sobretudo relacionado ao prestígio com alunos e a experiência como docentes, os professores passam a construir uma relação mais assimétrica com estes agentes do campo.

Categoria A.1.c.) Relacionamento com instâncias institucionais

$\mathrm{Na}$ terceira categoria, "Relacionamento com instâncias institucionais", foram alocados oito trechos de falas dos professores. A maioria delas diz respeito à quantidade de atividades assumidas quando o professor novato chega à instituição. Os professores apontaram como uma dificuldade assumir aulas de muitas disciplinas diferentes, além da quantidade maior de aulas que o iniciante assume. A relação de quem chega à instituição é assimétrica. O professor experiente, que se envolve com atividades de pesquisa e extensão, por ocupar uma posição superior no campo, caracterizada pelo volume de seu capital, determina a estrutura do campo em proporção ao seu peso, ou seja, na distribuição de aulas, assume uma quantidade que lhe permita ter tempo para desenvolver outras atividades, além do ensino. Resta aos ingressantes a 
pressão de assumirem responsabilidades deixadas de lado pelos agentes mais "poderosos" do campo, ou seja, mais atividades de ensino. Isso foi expresso por vários professores, entre eles, P9, que diz: "eu peguei muitas disciplinas diferentes, então preparar todas aquelas aulas, na semana era pouco tempo que eu tinha, eram 20 aulas e tinha que preparar umas 8 aulas diferentes, então era muita coisa. Assim, dai aquela dificuldade, sentia um peso em mim, o primeiro ano dando aula" [P9].

Ser um novato na docência universitária, que chega a este espaço social sem grande prestígio e reconhecimento, implica maior dedicação por conta de entender as regras próprias daquele campo, até possuir um capital cultural e simbólico que permita ao iniciante questionar as regras do jogo, que poderão ser mudadas de acordo com a influência que aquele agente obtiver no respectivo campo. Segundo Bourdieu, "Os novos que entram têm de pagar um direito de entrada que consiste no reconhecimento do valor do jogo [...] e no conhecimento (prático) dos princípios de funcionamento do jogo", o que pressupõe a "[...] importância do investimento, em tempo, em esforços, etc., que a entrada no jogo supõe” (BOURDIEU, 1983, p. 121).

Categoria A.1.d.) Gestão de sala de aula

A categoria "Gestão de sala de aula" teve nove trechos de entrevistas de P1, P4 e P6 incluídos. Destes, seis foram da entrevista de P6, e estão relacionados às dificuldades de relacionamento interpessoal e gestão de conflitos em sala de aula, e a maior exigência dos alunos de graduação em relação a isso. Por serem alunos de licenciatura, futuros professores, o docente se sentia pressionado a dar respostas mais incisivas na resolução de situações conflituosas na sala de aula e no seu modo de organizar a aula em si. Apareceram, também, nessa categoria, situações envolvendo a necessidade de disciplinar os alunos, ensinando-os a estudar e prosseguir no Ensino Superior, além da liberdade para aprendizagem individual dada por dois professores (P1 e P6) em suas aulas. As dificuldades de gestão de sala aula estão intimamente ligadas ao fator de iniciação à docência universitária, pois, mesmo para aqueles que tiveram formação para essa atividade relacionada ao processo de ensino-aprendizagem, gerir os procedimentos rotineiros nas atividades de sala de aula pode ser difícil, já que os alunos de cada turma são diferentes e reagem de maneiras diversas a uma mesma situação de ensino. Essas situações geradoras de conflitos são propulsoras de tensões dentro do campo da docência universitária, uma vez que a obtenção de prestígio junto aos alunos é um meio de aumentar o capital simbólico e a relação de poder junto aos demais agentes do campo.

Categoria A.1.e.) Insegurança didática

Na categoria "Insegurança didática", foram incluídas oito falas de 5 dos 10 professores (P2, P4, P5, P6 e P9), que abordam a dificuldade em ensinar um conteúdo específico: por desconhecerem estratégias de ensino, por não terem segurança de que a maneira com que ensinam é eficiente para aquele público e conteúdo, por não se sentirem aptos a ensinar alunos que têm praticamente a mesma idade dos professores, e considerarem que, para ensinar, é preciso saber tudo a respeito do assunto. Essa insegurança é gerada pela concepção clássica de que o professor é aquele que detém o conhecimento que será transmitido ao aluno (ZABALZA, 2004). Se ele fraquejar na maneira de transmitir o conhecimento, pode ser considerado um docente menos eficiente e ter uma posição inferior no próprio campo, sob o ponto de vista dos alunos. 
Categoria A.1.f.) Domínio dos conhecimentos a ensinar

Nessa mesma direção, de que o professor é o detentor do conhecimento, os docentes P1, P2, P3, P5, P6, P7, P8 e P9 fizeram 15 referências ao "Domínio dos conhecimentos a ensinar", apontando-o como uma tensão de início da docência. A lembrança dos professores era de estudarem muito, de se sentirem inseguros por não terem estudado algum conteúdo que agora teriam de ensinar. Essa tensão também se articula com o capital cultural de cada agente no campo, uma vez que, aquele que dispõe de um capital cultural e simbólico maior, terá maiores chances de conseguir prestígio e alcançar maior poder dentro do campo. Sentir-se com pouco domínio do conhecimento a ensinar, quando contratado como professor do Ensino Superior, pode significar a aceitação de que não é um agente capaz de contribuir e interferir nas decisões do campo.

\section{Eixo A: Núcleo 2. - Respostas às dificuldades}

Considerando as dificuldades que os professores disseram ter tido no início da docência universitária, buscamos, em seu discurso, ações implementadas para a superação dessas dificuldades, caracterizadas em quatro categorias.

Categoria A.2.g.) Envolvimento com outros agentes/instâncias institucionais

Alguns exemplos de como superar as dificuldades encontradas estão relacionados ao "Envolvimento com outros agentes/instâncias institucionais" (19 trechos de entrevistas de P2, P3, P5, P6, P7 e P8), e fazem referência a: conhecer a estrutura física e administrativa da instituição, assumir cargos administrativos, bom relacionamento com a chefia departamental, com os técnicos e professores, e com a influência que o envolvimento com a pós-graduação trouxe ao seu fazer docente. O professor P6 se refere, por exemplo, à participação de alunos de pós-graduação nas aulas da graduação: "quando eles começaram a vir, eu acho que já comecei a melhorar um pouquinho no jeito de ensinar, porque eles tem as aulas que eles apresentam, então eles mostram pra gente $e$ aí, às vežes, é um jeito que você não daria aquela aula" [P6].

Categoria A.2.h.) Esforço pessoal

$\mathrm{Na}$ categoria denominada "Esforço pessoal", foram incluídos doze trechos de entrevistas que apontavam para o esforço despendido, pelos professores, no início da docência, para se adequarem ao contexto e superarem os conflitos e dilemas enfrentados em sala de aula, no relacionamento com os alunos e colegas de trabalho. Os professores apontam, por exemplo, que incluíram conhecimentos específicos em suas disciplinas quando os alunos não os tinham aprendido em outras; que procuraram melhorar sua maneira de ensinar, chegaram a buscar apoio fora do espaço social da docência universitária para os problemas encontrados, reforçando a necessidade de investimento em tempo e esforços para serem reconhecidos como membros deste campo (BOURDIEU, 1983).

\section{Categoria A.2.i.) Experiência}

A "Experiência" foi apontada nove vezes pelos professores P2, P3, P5, P6 e P9 como fundamental para a superação de alguns de seus dilemas de docentes iniciantes: "na medida que fui dando as aulas, né, aprendi na marra" [P2]; "primeira vez, que eu fui dar a disciplina, eu nunca tinha dado a disciplina e não era da minha área, fui muito teórica, então eu pude comparar a segunda turma com a primeira, tudo que eu trabalhei diferente, dava artigo, dividia em grupos, eles tinham que explicar a técnica, foi diferente de quando só eu falava de teoria" [P9]. 
Categoria A.2.j.) Discussões e planejamentos coletivos

A categoria "Discussões e planejamentos coletivos" teve seis trechos incluídos que apontaram para a participação em grupo de pesquisa (P9) e para a discussão de aspectos específicos de alguma disciplina ministrada com colegas iniciantes e experientes (P2, P3, P6 e P7). A constituição de um grupo de discussão aponta para aquilo que é central num campo, um mesmo sentido de jogo, objetivos comuns, e é o que o sustenta o campo. As discussões são caracterizadas por divergências de pensamento, e são possibilidades profícuas de crescimento e ampliação do campo, alicerçado pela constituição do coletivo. Para Bourdieu (1983, p. 23), "todas as pessoas que estão cometidas num campo têm em comum um certo número de interesses fundamentais, a saber, tudo o que está ligado à própria existência do campo: daí uma cumplicidade objectiva que está subjacente a todos os antagonismos."

Categoria A.2.k.) Planejamento das ações didáticas

O "Planejamento das ações didáticas" foi o meio encontrado, pelos professores P1, P2, P6 e P7, para superarem as dificuldades do início da docência no Ensino Superior. P1, por exemplo, diz: "eu sempre procurei fazer muito disso, de preparar muito as minhas aulas, planejava rigorosamente a minha aula" [P1].

Em relação ao objetivo do trabalho e considerando todas as categorias incluídas no eixo A., cabe destacar a relação de dominante-dominado que os docentes mais experientes exercem sobre os mais novos, relação que não se caracteriza como dominante-subordinado, mas prioriza o valor e o potencial relativos de várias espécies rivais de capital que compõem a estrutura de determinado espaço social.

\section{Eixo B - Diferentes vivências a partir das experiências docentes anteriores}

Quanto ao questionamento "Há diferenças nessas vivências iniciais entre aqueles que tiveram experiências docentes anteriores à docência universitária?”, uma análise qualitativa foi realizada separadamente para os dois grupos: (a) docentes com experiência anterior; e (b) docentes sem experiência anterior.

Retomando os dados do Quadro 1, identificamos os professores pertencentes a cada grupo. No primeiro grupo, estão os docentes que não tiveram experiência na docência antes de lecionarem no Ensino Superior, composto por P2, P3 e P8. Embora P8 tenha dito que deu aulas particulares algumas vezes, nunca atuou numa escola, não precisou: gerenciar conflitos em sala de aula, preparar atividades para grupos de alunos, planejar ações didático-metodológicas para algum conteúdo e contexto específicos, nem se relacionar com colegas no ambiente profissional da escola. Ou seja, não necessitou mobilizar os conhecimentos considerados básicos para a docência, na perspectiva de Grossman (1990) e Shulman (1987).

Estes professores, em suas colocações a respeito das vivências iniciais como docentes do Ensino Superior, relatam dificuldades relativas à insegurança didática e o medo de não conseguirem cumprir as tarefas a eles atribuídas: "no começo eu era bastante insegura" [P2]; "estar lá diante dos alunos e dai, assim, sabe, na hora [...] você tem a dúvida e você não consegue passar" [P2]; "tinha que dar conta de um monte de curso com turmas diferentes, turmas grandes [...] falar de assuntos diversos né, e en ficava com medo! Ah será que eu vou saber dar aula" [P3].

Para P8, o que foi mais dificultoso no início da docência universitária foi o descrédito que os colegas mais experientes tinham com o novato: "os professores antigos [...] quando viam que a 
gente chegava eles falavam: Ah, não vai durar muito, um ou dois meses" [P8]; "porque parece que o professor que chega [...] ele tem mais vontade de trabalhar, de fazer as coisas, o professor que já está mais tempo na universidade, parece que não é bem assim [...] eu pensava assim, porque isso? [...] Será que eu vou adquirir isso com o tempo? Eu pensava, né. Uma vez. me falaram assim, você é nova” [P8].

Wanderley (1994), ao comentar sobre os diferentes agentes da comunidade universitária em nível nacional e internacional, diz que algumas características são comuns ao grupo dos professores. Ele aponta para características: da admissão de professores nos quadros docentes, da carreira de professor universitário, da relação entre ensinar e educar, e sobre a consciência e organização do corpo docente. Em relação a este último:

A realidade mostra que, ao lado de alguns professores minoritários sempre disponíveis, criativos, que se esforçam acima do que é exigível, que pesquisam, que renovam seus cursos, uma grande maioria permanece burocratizada e passiva. Outros centram suas vidas acadêmicas na subida de todos os degraus da carreira, ou nas disputas de poder interno. Formam-se assim igrejinhas, pequenos feudos, grupos de patrulhamento ideológico. (WANDERLEY, 1994, p. 53)

Por outro lado, os professores inexperientes reforçaram a importância do apoio de alguns colegas, o entusiasmo com a docência, e assumiram que aprenderam, na prática, o trabalho de um professor.

Já os docentes com alguma experiência na docência anterior ao ingresso no Ensino Superior no papel de professores, também tiveram dificuldades com o modo de ensinar, sentiram-se inseguros, avaliados a todo tempo pelos alunos e, até mesmo, pelos colegas.

Algo que foi comum entre os professores dos dois grupos foi a reclamação em relação à sobrecarga de trabalho assumida no início da docência, considerada grande e muito diversa (aulas em diferentes cursos, de diferentes áreas e com muitas turmas, por vezes, muito grandes também).

Considerar, nos planejamentos e ações didáticas, o contexto em que os alunos estão inseridos e suas aprendizagens anteriores para poder ensinar foi uma das diferenças entre os dois grupos de professores. Aqueles que já haviam lecionado em outros níveis de ensino conseguiram perceber essa necessidade, enquanto os que iniciaram a docência no Ensino Superior não relatam qualquer ação ou intenção relacionada a isso. $\mathrm{O}$ professor $\mathrm{P} 5$, referindo-se à capacidade de adequar o ensino ao público que se tem, diz que: "No primeiro ano, quando você chega do mestrado e doutorado, você chega num outro ritmo [...], então a tua capacidade intelectual aumentou tanto que você até perde o senso do que é fundamental e, com o tempo, eu acho, você vai voltando".

Em relação à adequação do nível dos conteúdos desenvolvidos nas aulas do Ensino Superior, P6 afirma: "eu vim de universidades grandes [...] e ai você chega aqui, fica um pouco assustada, mas tem uma coisa que me ajudava, como eu era devagar, eu sabia que tinha que estudar, preparar aula, então eu conseguia [...] trazer para um nivel mais baixo".

Outro professor faz referência ao replanejamento anual de sua disciplina, considerando a aprendizagem dos alunos com quem trabalhará: "eu não utilizo o mesmo planejamento no ano seguinte, eu sempre faço uma avaliação desse grupo, reconstruo" [P1].

Essa característica presente nos professores com experiências docentes anteriores reforça o papel da experiência na aprendizagem da docência, e expõe uma característica que 
deve ser básica aos professores quando planejam e estabelecem os objetivos de aprendizagem: é preciso considerar para quem determinado conteúdo será ensinado (que inclui o conhecimento de quem é este agente e o que ele já sabe), de modo a preparar ações didático-metodológicas que sejam efetivas para a/na aprendizagem. Referimos-nos ao conhecimento do contexto dos estudantes e do seu nível de aprendizado como um desafio, pois ao se assumir que o estudante acadêmico é um sujeito adulto, pressupõe-se que ele "tem um amplo background cultural. Isso implica que a universidade tem de elevar seu ensino para um alto nível, considerando as aprendizagens prévias dos alunos" (ZABALZA, 2004, p. 187).

\section{Eixo C - Relações instituídas entre os diferentes agentes}

Ao se buscar evidenciar quais as relações entre os professores em início de carreira com os diferentes agentes do campo (instituição, alunos e professores), percebeu-se que, no início da carreira, os colegas de trabalho são vistos como parceiros para trabalhos coletivos e apoio nas dificuldades encontradas na docência, como apontado pelos professores: "me chamou para conversar, dizendo que qualquer ajuda que eu precisasse ela estava à disposição" [P9]; "nós tínhamos e continuamos com essa cultura de encontros, reuniões e dentro do departamento, [...] sempre foi uma área muito unida, [...] nós fazemos reuniões de estudo mesmo" [P7]; "comecei do zero, mas você lê um livro, outro livro, aí discutia com a [cita nome de colegas], a gente tirava bastante dúvida” [P6].

Mas, também aparecem como agentes que não partilham objetivos de formação e criticam os novatos que buscam fazer atividades diferenciadas. A superioridade docente é vista pelos alunos e pelos próprios professores, que se sentem avaliados e exigidos pelos alunos, mas, que assumem que são exigentes para com os estudantes e percebem a sua dependência no processo de aprender a estudar na universidade. Na relação com a instituição, o item mais abordado é a quantidade de atividades assumidas pelos docentes quando chegam à universidade, relativas ao número de aulas assumidas, em diferentes cursos (todos os professores atuaram em, pelo menos, três cursos diferentes nos anos iniciais da docência universitária).

\section{Considerações finais}

As principais conclusões do trabalho apontam para características próprias, tensões e dificuldades do microcampo do trabalho docente do professor do Ensino Superior em início de carreira.

Diversas dificuldades estão relacionadas à gestão de sala de aula, como o relacionamento interpessoal, gestão de conflitos, disciplina dos alunos, liberdade para aprendizagem individual; à insegurança didática por desconhecer estratégias próprias para o ensino de conteúdos específicos que sejam eficientes para determinado público; e ao domínio dos conhecimentos a ensinar, caracterizados pela necessidade de estudar muito para poder lecionar uma disciplina e pela insegurança sentida pelos professores que não estudaram algum conteúdo que precisariam ensinar. Alguns exemplos de como superar essas dificuldades foram apontados pelos professores e estão relacionados: à dedicação ao planejamento das ações didáticas, ao envolvimento com colegas de trabalho para discussão de ações em sala de aula e apoio mútuo, participação em grupos de estudos, ao envolvimento com diferentes agentes institucionais, ao esforço pessoal e à aprendizagem propiciada pela experiência. 
Em relação às possíveis diferenças nas vivências iniciais entre aqueles professores que tiveram experiências docentes anteriores ao trabalho na universidade e aqueles professores que ainda não haviam lecionado, podemos ressaltar várias aproximações e semelhanças, no que diz respeito à insegurança didática, ao valor dado ao apoio (ou não) dos colegas de trabalho e ao número de atividades desempenhadas. A diferença percebida em vários dos professores experientes foi em relação à consciência da necessidade de reorganização das atividades didáticas e do seu modo de ensinar em função do contexto e nível de aprendizado dos estudantes acadêmicos.

Já sobre as relações instituídas entre os diferentes agentes do Campo da Docência Universitária, percebe-se que a relação com os alunos ainda é de superioridade do docente novato em relação aos alunos (é o professor que sabe o que precisa ser trabalhado e qual o melhor caminho para isso), e de dominação dos colegas professores mais experientes sobre os novatos no trabalho universitário. Com a instituição, a situação em alguma das extremidades do dipolo dominante-dominado é que rege as relações, e, por isso, o novato assume as funções a ele atribuídas sem muito questionamento. Essas relações de poder refletem, claramente, a diferenciação de capital cultural e simbólico de quem adentra um novo campo. As estruturas mais gerais de um campo na perspectiva de Bourdieu aparecem no Campo da Docência Universitária, de tal modo que ele pode ser assumido como um novo campo, que merece ser olhado e analisado mais calmamente sob o viés da sociologia desse autor. O professor iniciante no cenário universitário adentra o espaço social com pouco reconhecimento dos agentes, sobretudo por não ter ainda demonstrado "serviço" nesse espaço e, como forma de conquistar poder, envolve-se em atividades de diferente natureza, insere-se em grupos e empenha-se com bastante dedicação ao trabalho, para poder, quiçá um dia, questionar as regras do jogo e tornar-se influente no respectivo campo.

\section{Referências}

BALZAN, N. C. De estudante ao professor universitário: caminhos para a didática do ensino superior. Revista de Educação, Campinas, v. 1, n. 3, p. 7-24, 1997.

BARDIN, L. Análise de conteúdo. Lisboa: Edições 70, 2003.

BEHRENS, M. A. A formação pedagógica e os desafios do mundo moderno. In: MASETTO, M. (Org.). Docência na universidade. Campinas: Papirus, 2001. p. 57-68.

BOURDIEU, P. Questões de sociologia. Rio de Janeiro: Marco Zero, 1983.

Os usos sociais da ciência: por uma sociologia clínica do campo científico. São Paulo: Ed. da Unesp, 2004.

BRASIL. Lei no 9.394, de 20 de dezembro de 1996. Estabelece as diretrizes e bases da educação nacional. Diário Oficial da União, Brasília, 23 dez. 1996. 
Freire, L. I. F.; Fernandez, C.

COORDENAÇÃO DE APERFEIÇOAMENTO DE PESSOAL DE NÍVEL SUPERIOR. Portaria No 52, de 26 de setembro de 2002. Brasília, 2002. Disponível em: <https://www. capes.gov.br/images/stories/download/relatorios/Portaria_52_Regulamento_DS.pdf $>$. Acesso em: 13 out. 2014.

CUNHA, M. I. Formatos avaliativos e concepção de docência. Campinas: Autores Associados, 2005.

FELDKERCHER, N.; ZANCHET; B. M. B. A. De estudante a jovem professor iniciante na UFPEL: uma proposta de pesquisa. In: ENCONTRO DE PÓS-GRADUAÇÃO DA UNIVERSIDADE FEDERAL DE PELOTAS, 14., 2012, Pelotas. Anais... Disponível em: <http://www.ufpel.edu.br/enpos/2012/anais/pdf/CH/CH_00301.pdf>. Acesso em: 25 jun. 2013.

GROSSMAN, P. L. The making of a teacher: teacher knowledge and teacher education. New York: Teachers College Press, 1990.

MIZUKAMI, M. G. N. Formadores de professores, conhecimentos da docência e casos de ensino. In: MIZUKAMI, M. G. N.; REALI, A. M. M. R. (Org.). Formação de professores, práticas pedagógicas e escola. São Carlos: Ed. UFSCar, 2002. p. 151-174.

MONTAGNER, M. A.; MONTAGNER, M. I. A teoria geral dos campos de Pierre Bourdieu: uma leitura. Tempus: actas de saúde coletiva, Brasília, v. 5, n. 2, p. 255-273, 2011.

NÓVOA, A. Vidas de professores. Porto: Porto Editora, 1995.

OLIVEIRA, E. C. Formadores de professores de língua inglesa: uma experiência de colaboração e reflexão. 2008. 234 f. Tese (Doutorado em Letras e Estudos Linguísticos) Universidade Federal de Minas Gerais, Belo Horizonte, 2008.

PIMENTA, S. G.; ANASTASIOU, L. G. C. Docência no ensino superior. São Paulo: Cortez, 2002.

SHULMAN, L. S. Knowledge and teaching: foundations of the new reform. Harvard Educational Review, Cambridge, v. 57, n. 1, p. 1-21, 1987.

WANDERLEY, L. E. W. O que é universidade. 9. ed. São Paulo: Brasiliense, 1994.

ZABALZA, M. A. O ensino universitário: seu cenário e seus protagonistas. Porto Alegre: Artmed, 2004.

Artigo recebido em 14/10/13. Aceito em 22/07/14. 